Proceedings

\title{
DNA Barcoding of Olive Lace Bugs (Hemiptera: Tingidae) Re- Veals Previously Unknown Species Diversity in South Africa ${ }^{\dagger}$
}

\author{
Vaylen Hlaka * and Barbara van Asch
}

Citation: Hlaka, V.; van Asch, B. DNA Barcoding of Olive Lace Bugs (Hemiptera: Tingidae) Reveals Previously Unknown Species Diversity in South Africa, in Proceedings of the 1st International Electronic Conference on Entomology, 1-15 July 2021, MDPI: Basel, Switzerland, doi:10.3390/IECE-10610

Published: 6 July 2021

Publisher's Note: MDPI stays neutral with regard to jurisdictional claims in published maps and institutional affiliations.

Copyright: () 2021 by the authors. Submitted for possible open access publication under the terms and conditions of the Creative Commons Attribution (CC BY) license (http://creativecommons.org/licenses /by/4.0/).

\author{
Department of Genetics, Stellenbosch University, Private Bag X1, Matieland 7602, South Africa. \\ * Correspondence: 23935731@sun.ac.za \\ + Presented at the 1st International Electronic Conference on Entomology (IECE 2021), 1-15 July 2021; \\ Available online: $\underline{\text { https://iece.sciforum.net/. }}$
}

\begin{abstract}
Multiple olive lace bug species (Hemiptera: Tingidae) feed on Oleaceae in Southern Africa but the diversity of olive lace bugs in South Africa is not fully known. Olive lace bugs were collected from wild and cultivated olive trees, and tentatively identified as Cysteochila lineata, Neoplerochila sp., N. paliatseasi and Plerochila australis. DNA barcodes and mitogenomes were generated for each species and used for phylogenetic analyses and estimates of genetic divergence, along with data publicly available for Tingidae. The utility of DNA barcoding for species identification in Tingidae was supported. The mitochondrial phylogeny of Tingidae recovered the four olive lace bugs as closely related species.
\end{abstract}

Keywords: Olea europaea; mitogenomics; phylogenetics

\section{Introduction}

Lace bugs (Hemiptera: Tingidae) include approximately 2,500 species in 300 genera distributed worldwide [1]. Adults and nymphs feeding on the underside of leaves are detrimental to plant vitality, and heavy infestations may cause host defoliation. Lace bugs are highly monophagous and a species will feed on the same type of plant. Lace bugs feeding on Oleaceae are mostly found in sub-Saharan Africa, and include species in the genera Catoplatus, Cysteochila, Olastrida and Caffrocysta. Sub-Saharan Africa harbours a diversity of native insects associated with Olea including several species of olive lace bugs, olive fruit flies, olive flea beetles, and parasitoid, hyperparasitoid and olive seed wasps [2-5].

In the Western Cape province of South Africa, the most important olive-producing region of the continent, lace bugs affecting wild and cultivated olive trees (Olea europaea) have been reported as Plerochila australis (Distant, 1904) [6] and Neoplerochila paliatseasi (Rodrigues, 1981) [7]. Neoplerochila paliatseasi is probably distributed countrywide in South Africa, as it was found in the Limpopo, North West and Western Cape [7-8], and Gauteng provinces (present study). Plerochila australis likely also has a countrywide distribution as it was reported in the Northern Cape, Gauteng, Limpopo, Mpumalanga, and North West [9], and in the Western Cape provinces (present study).

Olive lace bugs are currently not a major concern for South African olive growers, and the most important olive producing regions in the world (the Mediterranean Basin and California) are free from these pests, but they may become a threat outside of their original geographic range. Under the right circumstances, olive lace bugs can become a serious pest, as for example Froggattia olivinia which moved from its native host Notelaea longifolia (Oleaceae) to cultivated olive trees and African wild olives in Australia, when these were imported and disseminated in the country [10].

This study aimed to assess the diversity of olive bug species found on wild and cultivated olives in South Africa using morphological identification and DNA barcoding, and 
to investigate the phylogenetic position of those species within the family Tingidae using new and publicly available mitogenome sequences.

\section{Materials and Methods}

\subsection{Specimen collection, morphological identification, and DNA extraction}

Olive lace bugs were haphazardly collected in nine areas in the Western Cape (cultivated and wild olive trees) and one site in Pretoria (wild olive trees) between November 2015 and March 2020, and stored individually in $100 \%$ ethanol at $-20^{\circ} \mathrm{C}$ until downstream analyses. Morphological identifications were performed by E. Guilbert (Natural History Museum, Paris) based on the original descriptions, and pictures of type material and collections available. DNA was extracted from individual specimens using a standard phenol-chloroform method and stored at $-20^{\circ} \mathrm{C}$ until further use.

\subsection{Sequencing, assembly, and annotation of complete mitogenomes}

The complete mitochondrial genomes for one specimen each of C. lineata, P. australis and Neoplerochila sp. were sequenced using the Ion Torrent ${ }^{\mathrm{TM}} \mathrm{S}^{\mathrm{TM}}$ platform (ThermoFisher Scientific, Waltham, MA, USA) available at the Central Analytical Facilities of Stellenbosch University, South Africa. The NGS reads for each species were mapped against the complete mitogenome of N. paliatseasi (MN794065) and assembled and annotated using Geneious Prime v2021.1.

\subsection{Phylogenetic reconstruction}

The phylogenetic position of C. lineata, N. paliatseasi, Neoplerochila sp. and P. australis was assessed in the context of Tingidae using the other 15 mitogenomes available for the family on GenBank as of October 2020, with Apolygus lucorum and Adelphocoris fasciaticollis (Hemiptera: Miridae) as outgroups. The final sequence alignment included the 13 protein-coding genes, and was used to generate two sub-datasets: PCG123 (all codon positions) and PCG12 (excluding the 3rd codon position). Bayesian Inference (BI) was performed in MrBayes v3.2.7a [11] under the GTR + GAMMA + I substitution model. The confidence in the tree topologies was estimated as Bayesian posterior probability (BPP).

\subsection{DNA barcoding}

The new DNA barcodes generated for C. lineata $(n=25), P$. australis $(n=32), N$. paliatseasi $(n=3)$ and Neoplerochila sp. $(n=3)$ were used in genetic clustering analysis and estimates of intra- and interspecific genetic diversity. New species-specific PCR primers were designed for DNA barcoding of P. australis and C. lineata, based on their mitochondrial genomes. Neoplerochila paliatseasi and Neoplerochila sp. were barcoded using PCR primers specific to N. paliatseasi designed in a previous study [7]. PCR amplifications were performed in a total volume of $5 \mu \mathrm{L}$ containing 1X of KAPA2G Robust HotStart Ready Mix PCR kit (KAPA Biosystems), $0.5 \mu \mathrm{M}$ of each primer, $0.5 \mu \mathrm{L}$ of MilliQ H2O, and $1.0 \mu \mathrm{L}$ of template DNA ( 100 ng), as follows: 3 min at $95^{\circ} \mathrm{C} ; 35$ cycles of $15 \mathrm{~s}$ at $95^{\circ} \mathrm{C}, 15 \mathrm{~s}$ at $58^{\circ} \mathrm{C}$ for C. lineata and $54^{\circ} \mathrm{C}$ for N. paliatseasi and P. australis, $1 \mathrm{~min}$ at $72^{\circ} \mathrm{C}$; and a final extension of $1 \mathrm{~min}$ at $72^{\circ} \mathrm{C}$. PCR products were sequenced using the reverse primers with the BigDye Terminator v3.1 Cycle Sequencing Kit (Applied Biosystems, Waltham, MA, USA) at the Central Analytical Facilities of Stellenbosch University.

All DNA barcodes assigned to Tingidae were downloaded from BOLD Systems (http://v3.boldsystems.org/, accessed in October 2020) to provide a broader context for the intra- and interspecific divergence and genetic clustering patterns of the four olive lace bug species found in South Africa. After filtering for sequences identified to species level, sequences with a minimum length of $500 \mathrm{bp}$ overlapping the standard COI barcoding region and species represented by a minimum of three sequences, the final dataset $(n=349)$ included 30 species across 18 genera. Sequences were aligned with the MAFFT algorithm [12] in Geneious Prime. Genetic clustering was assessed using a Neighbor-Joining (NJ) tree in MEGA X [13] under the Kimura 2-parameter (K2P) model [14]. Intra- and interspecific genetic divergences were estimated as p-distances (\%) under the K2P model on 
MEGA X. Statistical support for the NJ tree and for p-distances were calculated from 1,000 bootstrap replicates.

\section{Results and Discussion}

Olive lace bug infestations are known to feed on cultivated olive trees in South Africa, but the diversity of the species has been incompletely described. This study follows up on previous reports by confirming the identity and presence of $\mathrm{P}$. australis and N. paliatseasi, and additionally reporting the presence of $\mathrm{C}$. lineata and an undetermined species of Neoplerochila genetically distinct from N. paliatseasi. The phylogenetic position of these olive lace bugs within Tingidae was assessed in the context of all mitogenomes available for the family on GenBank as of October 2020.

\subsection{DNA barcoding in Tingidae}

The genetic clustering analyses showed that all species formed monophyletic clusters with high statistical support (Figure 1). Intraspecific genetic divergence showed that most species $(83 \%)$ had intraspecific maximum p-distances below $2 \%$, and only four species fell between $2 \%$ and $3 \%$, indicating high level of consistency in specimen identification and good quality of the data available on BOLD Systems. Only one case of potential misidentification or cryptic diversity was found (Derephysia foliacea, maximum p-distance $=$ $9.28 \%$ ) due to the presence of a single highly diverged sequence (BOLD Systems record GMGMM1352-14). Thresholds of intra- and interspecific divergence values are arbitrary, and no fixed threshold can be universally applied [15]. In the case of Tingidae, the data analysed here indicates that the range of maximum p-distances between $2 \%$ and $3 \%$ is a reasonable proxy for inferring conspecificity among sequences. 


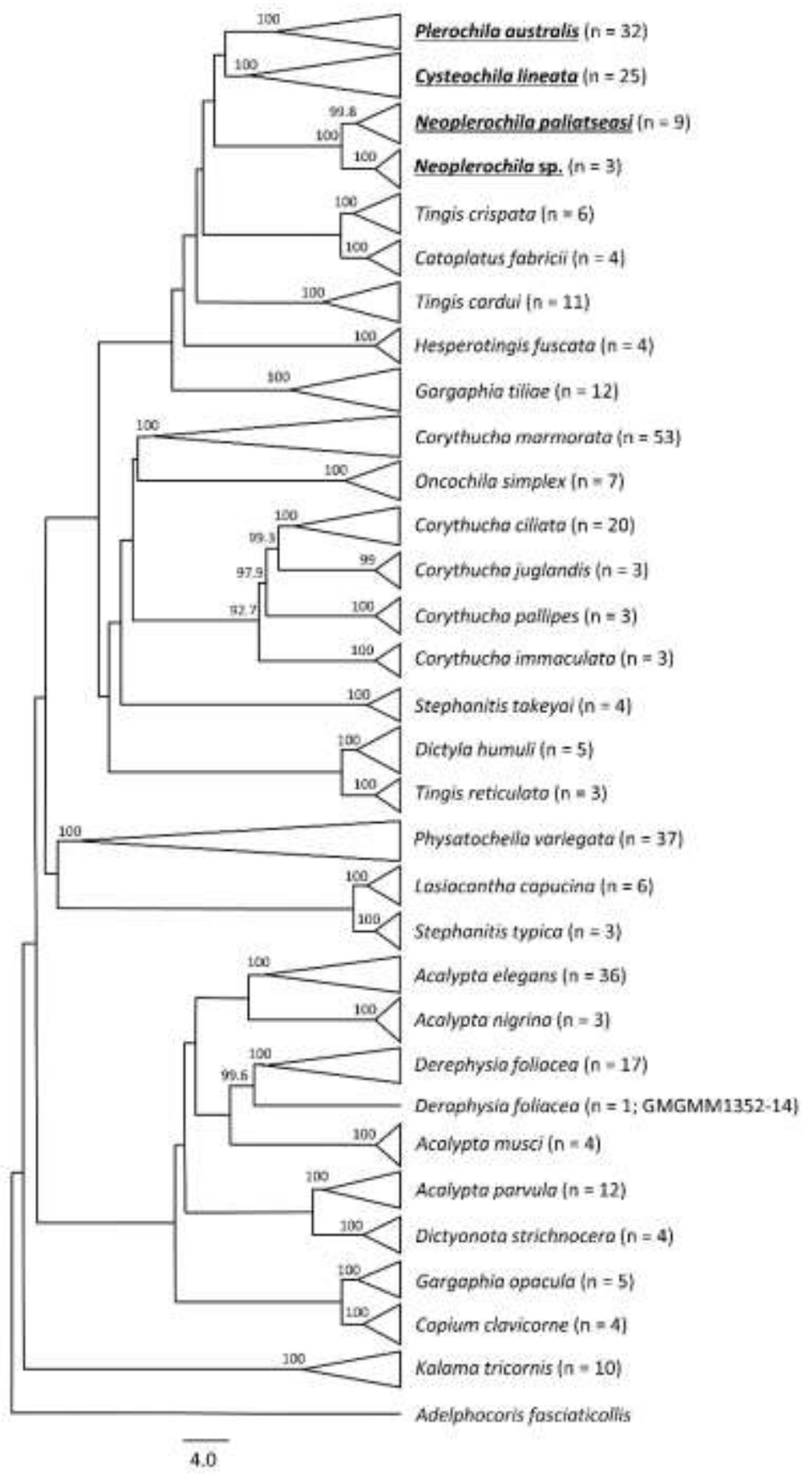

Figure 1. Neighbour-joining tree of lace bug species (Hemiptera: Tingidae) based on an alignment of standard COI barcoding sequences (501 bp). The analysis included 349 sequences representing 30 species in 18 genera retrieved from BOLD Systems and the new sequences of the olive lace bugs Cysteochila lineata, Neoplerochila paliatseasi, Neoplerochila sp. and Plerochila australis generated in this study. Triangles represent collapsed groups of sequences belonging to the same species (max p-distance $<3 \%$ ). Nodal support was based on 1,000 bootstrap replicates (only values $>90 \%$ are displayed).

\subsection{Phylogeny of Tingidae}

The phylogenetic position of C. lineata, N. paliatseasi, Neoplerochila sp. and P. australis found in South Africa was recovered in the context of other Tingidae. The PCG123 tree had high statistical support for most nodes $(\mathrm{BPP}=1)$ except for the deep divergence within the two main branches in Tingini and the unresolved position of the sister species 
Ammianus toi and Perissonemia borneenis, which was resolved in the PCG12 tree (Figure 2).
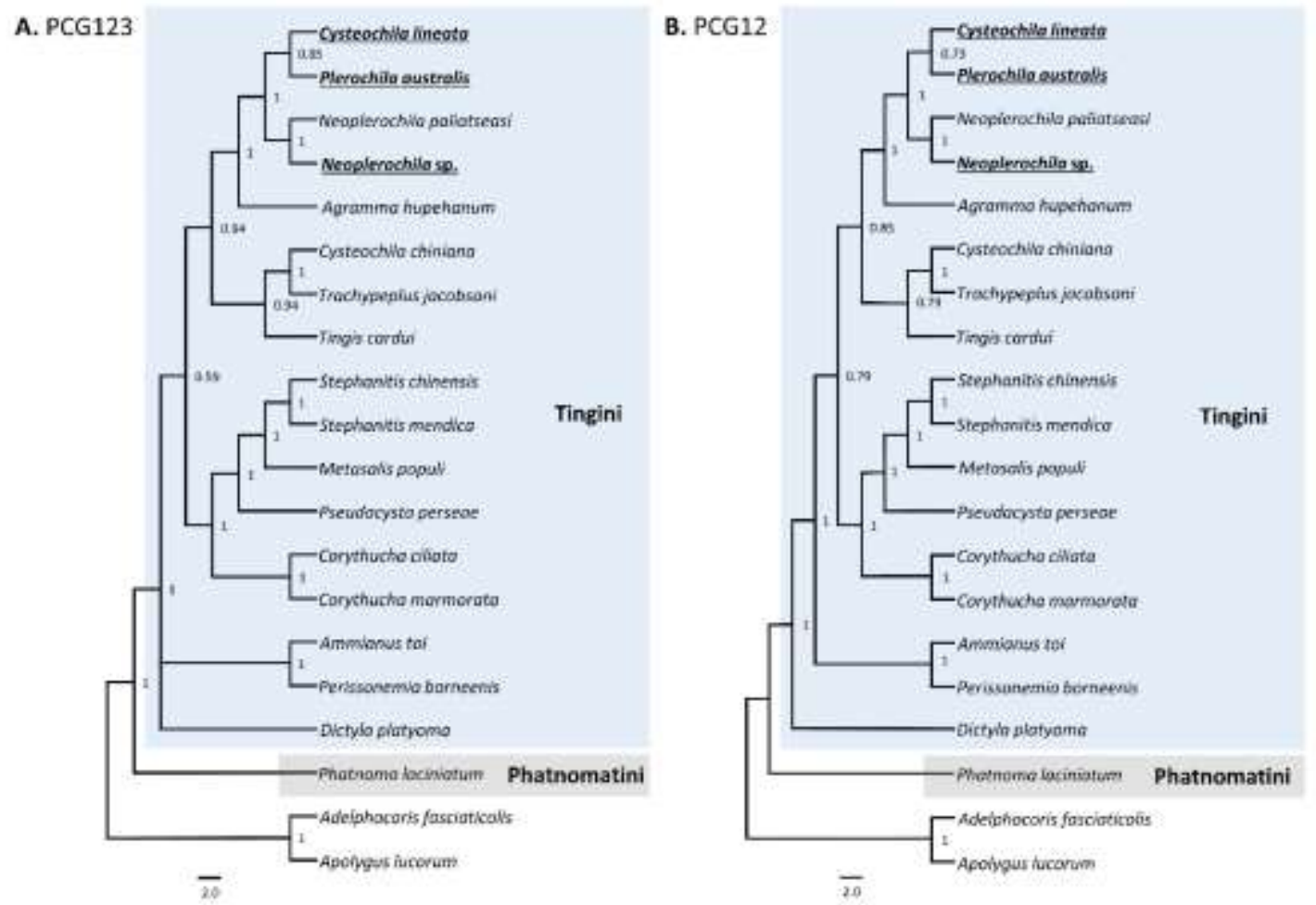

Figure 2. Bayesian phylogenetic trees of Tingidae based the complete complement of 13 protein-coding genes of 18 new and publicly available mitochondrial genomes for the family. Nodal support is given as Bayesian posterior probability. (a) Tree was based on the three codon positions; (b) Tree was based on the $1^{\text {st }}$ and $2^{\text {nd }}$ codons positions.

The general topology of the trees is in broad agreement with previous studies [7;16]. The four olive lace bugs were placed in the same phylogenetic cluster, and the genus Neoplerochila was monophyletic with high statistical support. However, the genus Cysteochila was not monophyletic and C. lineata was recovered as a sister species to P. australis but C. chiniana was placed in a different cluster with Tingis jacobsoni and T. cardui. This result shows that the olive lace bugs C. lineata, P. australis, N. paliatseasi and Neoplerochila sp. have a recent common mitochondrial ancestor and indicates that adaptation to feeding on Olea may have a common evolutionary origin. To confirm this hypothesis, it will be necessary to determine the phylogenetic position of other African Tingidae known to feed on Oleaceae, namely Neoplerochila millari Göllner-Scheiding 2007, Neoplerochila dispar Duarte Rodrigues, 1982, Neoplerochila weenenana (Drake, 1953), Physatocheila namibiana Duarte Rodrigues 1982 and Plerochila horvathi (Schouten 1907), and the Australian olive lace bug F. olivinia Froggatt, 1901.

Author Contributions: B.v.A. conceptualized the study and V.H. performed field and laboratory work. Both authors performed data analyses, contributed to the preparation of this manuscript and approved the final version for publication.

Funding: This research was funded by the SA Olive Industry Association and the Western Cape Alternative Crop Fund. VH received partial financial support from the National Research Foundation of South Africa.

Informed Consent Statement: Not applicable.

Data Availability Statement: The DNA sequences generated in this study were not yet made publicly available. 
Acknowledgments: The authors are grateful to Eric Guilbert for morphological identification of specimens.

Conflicts of Interest: The authors declare no conflict of interest.

\section{References}

1. Guilbert, E.; Damgaard, J. and D'Haese, C.A. Phylogeny of the lacebugs (Insecta: Heteroptera: Tingidae) using morphological and molecular data. Syst. Entomol. 2014, 39, 431-441.

2. Copeland, R.; White, I.M.; Okumu, M.; Machera, P.; Wharton, R.A. Insects associated with fruits of the Oleaceae (Asteridae , Lamiales) in Kenya, with special reference to the Tephritidae (Diptera). Bishop Museum Bull. Entomol. 2004, 12, $135-164$.

3. Mkize, N.; Hoelmer, K.A.; Villet, M.H. A survey of fruit-feeding insects and their parasitoids occurring on wild olives, Olea europaea ssp. cuspidata, in the Eastern Cape of South Africa. Biocontrol Sci. Technol. 2008, 18, 991-1004.

4. Teixeira da Costa, L.; Powell, C.; van Noort, S.; Carlo Costa, C.; Sinno, M.; Caleca, V.; Rhode, C.; Kennedy, R.J.; van Staden, M.; van Asch B. The complete mitochondrial genome of Bactrocera biguttula (Bezzi) (Diptera: Tephritidae) and phylogenetic relationships with other Dacini. Int. J. Biol. Macromol. 2019, 126, 130-140.

5. Powell, C.; Caleca, V.; Knipe, M.; Rhode, C.; Allsopp, E.; van Asch, B. DNA-Based identification of larvae offers insights into the elusive lifestyles of native olive seed wasps in South Africa. African Entomol. 2020, 28, 433-446.

6. Addison, M. F.; Addison, P. and Barnes, B. N. Olive, in Insects of Cultivated Plants and Natural Pastures in Southern Africa, $1^{\text {st }}$ ed; Prinsloo, G. L. and Uys, V.M. Entomological Society of Southern Africa, Pretoria, South Africa, 2015; pp. $394-405$.

7. Langley, J.; Cornwall, M.; Powell, C.; Costa, C.; Allsopp, E.; van Noort, S.; Guilbert, E.; van Asch, B. First report of the lace bug Neoplerochila paliatseasi (Rodrigues,1981) (Hemiptera: Tingidae) infesting cultivated olive trees in South Africa, and its complete mitochondrial sequence. Zootaxa 2020, 4722, 443-462.

8. Göllner-Scheiding, U. Die arten der afrotropischen gattung Neoplerochila Duarte Rodrigues, 1982 (Insecta, Heteroptera, Tingidae, Tinginae). Beiträge zur Entomologie, 2007, 57, 419-428.

9. Deckert, J.; Gollner-Scheiding, U. Lace bugs of Namibia (Heteroptera, Tingoidea, Tingidae). Denisia, 2006, 50, 823-856.

10. Spooner-Hart, R.; Tesoriero, L.; Hall, B.; Page, F.; Learmonth, S.; Conlan, D. Progress towards pest and disease management in Australian olive production. Adv. Hort. Sci. 2002 16, 218-224.

11. Ronquist, F.; Huelsenbeck, J.P. MrBayes 3: Bayesian phylogenetic inference under mixed models. Bioinformatics 2003, 19, 15721574.

12. Katoh, K.; Standley, D.M. MAFFT multiple sequence alignment software version 7: Improvements in performance and usability. Mol. Biol. Evol. 2013, 30, 772-780.

13. Kumar, S.; Stecher, G.; Li, M.; Knyaz, C.; Tamura, K. MEGA X: Molecular evolutionary genetics analysis across computing platforms. Mol. Biol. Evol. 2018, 35, 1547-1549.

14. Kimura, M. A simple method for estimating evolutionary rates of base substitutions through comparative studies of nucleotide sequences. J. Mol. Evol. 1980, 16, 111-120.

15. Meier, R. Shiyang, K.; Vaidya, G.; Ng, P.K. DNA barcoding and taxonomy in Diptera: A tale of high intraspecific variability and low identification success. Syst. Biol. 2006, 55, 715-728.

16. Lin, A.; Zhao, X.; Song, N. The complete mitochondrial genome of Corythucha marmorata (Hemiptera: Tingidae). Mitochondrial DNA Part B 2017, 2, 897-899. 